\title{
Effects of pan-frying in margarine and olive oil on the fatty acid composition of cod and salmon
}

\author{
Isabelle Sioen ${ }^{\mathrm{a}, \mathrm{b}, *}$, Lindsey $\operatorname{Haak}^{\mathrm{c}}$, Katleen Raes ${ }^{\mathrm{c}}$, Caroline Hermans ${ }^{\mathrm{a}}$, \\ Stefaan De Henauw ${ }^{b}$, Stefaan De Smet ${ }^{\mathrm{c}}$, John Van Camp ${ }^{\mathrm{a}}$ \\ a Department of Food Safety and Food Quality, Ghent University, Coupure Links 653, B-9000 Ghent, Belgium \\ ${ }^{\mathrm{b}}$ Department of Public Health, Ghent University, UZ - 2 Blok A, De Pintelaan 185, B-9000 Ghent, Belgium \\ ${ }^{\mathrm{c}}$ Department of Animal Production, Ghent University, Proefhoevestraat 10, B-9090 Melle, Belgium
}

Received 14 March 2005; received in revised form 15 June 2005; accepted 15 June 2005

\begin{abstract}
Effects on the fatty acid composition of cod ( Gadus morhua) and salmon fillets ( Salmo salar) after pan-frying in margarine and olive oil were determined. The fatty acids of the margarine used were 55.5\% saturated (SFA), 33.0\% mono-unsaturated (MUFA) and $11.5 \%$ polyunsaturated (PUFA). The olive oil used contained 15.4\% SFA, 76.1\% MUFA and 8.5\% PUFA. Using margarine or olive oil increased the SFA and MUFA percentages, respectively, in both species. For cod fillets (lean), pan-frying increased the fat content $(0.55-4.15 \mathrm{~g} / 100 \mathrm{~g}$ and $0.55-2.30 \mathrm{~g} / 100 \mathrm{~g}$ before and after pan-frying, with margarine and olive oil, respectively), whereas, for salmon fillets (fat), it decreased (13.91 to $10.57 \mathrm{~g} / 100 \mathrm{~g}$ and 15.35 to $12.95 \mathrm{~g} / 100 \mathrm{~g}$ before and after pan-frying with margarine and olive oil, respectively). In conclusion, the culinary fat selection affects the total fatty acid content and composition of the prepared fish fillet. (C) 2005 Elsevier Ltd. All rights reserved.
\end{abstract}

Keywords: Salmon; Cod; Pan-frying; Fatty acids; Culinary fat; Effect of processing

\section{Introduction}

A regular consumption of fish (mainly fatty fish) is recommended in view of its high content of long chain omega-3 (n-3) PUFA, especially eicosapentaenoic acid (EPA, C20:5n-3) and docosahexaenoic acid (DHA, C22: $6 n-3)$. No other food group is naturally as rich in $n-3$ PUFA as are fish and other seafood (Cunnane \& Griffin, 2002). The regular consumption of these $n-3$ PUFA is considered to be important because of their role in the prevention of several degenerative diseases which are becoming more common in Western populations (including cardiovascular and inflammatory disorders, cancer and stroke) (Din, Newby, \& Flapan, 2004; Kris-Etherton, Harris, \& Appel, 2003).

\footnotetext{
${ }^{*}$ Corresponding author. Tel.: +32 924024 23; fax: +329 2404994

E-mail address: Isabelle.Sioen@UGent.be (I. Sioen).
}

Several studies were undertaken to determine the effects of different cooking methods on the fatty acids of fish species, in particular deep fat-frying and oven-baking (Agren \& Hanninen, 1993; Aro et al., 2000; Candela, Astiasaran, \& Bello (1997, 1998); Gall, Otwell, Koburger, \& Appledorf, 1983; Mai, Shimp, Weihrauch, \& Kinsella, 1978; Mustafa \& Medeiros, 1985; Sanchez-Muniz, Viejo, \& Medina, 1992). Yet, less information on the effect of pan-frying can be found. Only Agren and Hanninen (1993), Al Saghir et al. (2004) and Mai et al. (1978) have studied the effects of pan-frying on the fatty acid profile of lake trout, white sucker, bluegill, rainbow trout, vendace, pike and salmon. Pan-frying is a frequently applied method and gives flavour characteristics to the food that are highly appreciated by the consumers.

The objective of the present study was to investigate the effect of pan-frying, with two different culinary fats, on the fatty acids of cod (Gadus morhua) and Atlantic 
salmon (Salmo salar). In Belgium, cod and salmon are the most eaten species of lean and fatty fish, respectively (Hoge Gezondheidsraad, 2004). Using these two species, in the same setting made it also possible to investigate the effect of the fat content on the compositional changes of fish fillets during processing. Candela et al. $(1997,1998)$ studied the effect of processing on these species, but only looked at the effects of deep-fat frying. In Belgium, pan-frying is another popular cooking method to prepare fish and fish derived foods. In this study more saturated margarine and an unsaturated vegetable oil were used for pan-frying. Comparing the use of culinary fats with different fatty acid profiles is relevant to investigate their influence on the fatty acid profile of the food after preparation. Moreover, in Belgian households, the use of saturated fats for pan-frying is being increasingly replaced by the use of more healthy unsaturated vegetable oils, especially olive oil.

\section{Materials and methods}

\subsection{Samples}

Frozen fish fillets of cod and salmon with an identified origin were chosen as samples for this study, since the fat content and the fatty acid composition of fish can vary a lot with season, age and origin of the species (Bandarra, Batista, Nunes, Empis, \& Christie, 1997; Hamre, Lie, \& Sandnes, 2003; Nettleton \& Exler, 1992; Olsson, Olsen, Carlehog, \& Ofstad, 2003). The fillets were bought in Belgian stores in September, 2003. The cod fillets originated from the northern part of the Atlantic Sea and were individually packed and had a mean weight of $96.99 \pm 1.84 \mathrm{~g}$ and a volume of $8 \times 6 \times 2 \mathrm{~cm}^{3}$. The salmon fillets originated from an aquaculture farm in Norway. They were vacuum-packed and had a mean weight of $147.44 \pm 9.14 \mathrm{~g}$ and a volume of $13 \times 5 \times 2.5 \mathrm{~cm}^{3}$. The same form and thickness of the different samples of the same species was considered necessary for achieving an identical time-temperature profile in the standardised cooking process. The samples were stored at $-18^{\circ} \mathrm{C}$. Before frying, $20.0 \mathrm{~g}$ of each fillet was taken and stored separately at $-18^{\circ} \mathrm{C}$ for further analyses on raw samples. As culinary fat, a classic olive oil $(100 \%$ olive oil) and a classic margarine were used. According to the label, the margarine consisted of palm oil, palm kernel oil, colza oil and coconut oil in an unspecified ratio (our analysis showed a total fat content of $83.0 \pm 1.5 \%$ ).

\subsection{Cooking procedures}

For all the frying experiments, a Tefal ${ }^{\circledR}$ frying pan $(\varnothing=20 \mathrm{~cm})$ was used on the same electrical heating unit. After each frying process, the pan was cleaned in the same way (first, the fat that remained in the pan was collected with a spatula and afterwards the pan was cleaned with a paper towel to remove all fat). During frying the core temperature of the fillets was recorded. The temperature at the surface of the heating unit was $234{ }^{\circ} \mathrm{C}$ for the cod samples and $190{ }^{\circ} \mathrm{C}$ for the salmon samples. The lower heating unit temperature for the salmon samples was needed to avoid burning. Before pan-frying the fillets were taken out of the freezer and kept for $20 \mathrm{~min}$ at room temperature. The amount of culinary fat used for pan-frying was equal to approximately $5 \%$ of the sample weight, which means $5.0 \mathrm{~g}$ of fat for the cod fillets and $6.5 \mathrm{~g}$ of fat for the salmon fillets. The cod samples $(n=7)$ were pan-fried during $10 \mathrm{~min}$, and turned once after $5 \mathrm{~min}$. The mean core temperature of the cod samples after pan-frying was $63.4 \pm 7.8^{\circ} \mathrm{C}$. The salmon samples $(n=6)$ were panfried for $16 \mathrm{~min}$ and turned each $4 \mathrm{~min}$, resulting in a mean core temperature of the salmon samples of $63.3 \pm 7.7^{\circ} \mathrm{C}$ after pan-frying. The salmon fillets had to be pan-fried longer before reaching the same final core temperature because they were thicker and they had a different composition, which gave a different specific heat. After pan-frying, $20.0 \mathrm{~g}$ of each fried sample was weighed and frozen at $-18^{\circ} \mathrm{C}$ prior to fatty acid analyses. The remaining fat in the pan was collected, weighed and analysed.

\subsection{Analytical procedures}

Before the lipid extraction, each sample was minced. Extraction of the total lipids was done using chloroform/methanol $(2 / 1 ; \mathrm{v} / \mathrm{v})$ according to the method of Folch, Lee, and Sloane-Stanley (1957) and after extraction they were methylated as described by Raes, De Smet, and Demeyer (2001). Heptadecanoic acid (C17:0) (Nucheck-prep, Inc., USA) was used as internal standard to quantify the fatty acids present in the fish samples. The methylated extract (fatty acid methyl esters) of each sample was analysed by gas chromatography in duplicate and than the mean value was calculated. A GC 3380 (Varian) gas chromatograph was used with a BPX 70 column $(50 \mathrm{~m} \times 0.22 \mathrm{~mm} \times 0.2 \mu \mathrm{m})$ and an injector temperature of $230^{\circ}, \mathrm{H}_{2}$ as carrier gas, and a temperature programme of $140{ }^{\circ} \mathrm{C}$ from $1 \mathrm{~min}$, followed by an increase of $2{ }^{\circ} \mathrm{C} /$ min to $168^{\circ} \mathrm{C}$ and held there for $50 \mathrm{~min}$. Peaks were identified by comparing the retention times with those of a standard mixture of commercial fatty acid methyl esters (GLW 68 D, Nu-check-prep, Inc., USA) and their areas were automatically integrated.

\subsection{Recoveries}

For each fatty acid measured in the different samples, the recovery was calculated as follows: 
Recovery $(\%)=100 \cdot\left(C_{\mathrm{F}} \cdot g_{\mathrm{F}}+C_{\text {fatres }} \cdot g_{\text {fatres }}\right) /\left(C_{\mathrm{R}} \cdot g_{\mathrm{R}}\right.$

$$
\left.+C_{\text {fat }} \cdot g_{\text {fat }}\right) \text {, }
$$

where $C_{\mathrm{R}}$ and $C_{\mathrm{F}}$ are the concentrations of the fatty acids $(\mathrm{g} / 100 \mathrm{~g})$ in the raw sample $(\mathrm{R})$ and the fried sample $(\mathrm{F})$, respectively. $C_{\text {fat }}$ and $C_{\text {fatres }}$ are the concentrations of the fatty acids $(\mathrm{g} / 100 \mathrm{~g}$ sample) in the culinary fat before (fat) and after pan-frying (fatres), respectively. These concentrations are multiplied by the mass $\left(g_{\mathrm{R}}, g_{\mathrm{F}}\right)$ of the raw or fried sample and the mass $\left(g_{\text {fat }}, g_{\text {fatres }}\right)$ of the culinary fat before or after pan-frying.

\subsection{Statistical analyses}

Statistical analysis was performed using SPSS software for windows (release 11.0, SPSS Inc., USA). The changes in fatty acid content before and after processing were tested by using a paired $T$-Test.

\section{Results}

\subsection{Pan frying in margarine}

The fatty acid contents of cod and salmon before and after pan-frying in margarine are shown in Tables 1 and 2. The margarine used in this study was a saturated culi- nary fat. Of the total fatty acids, 55.5\% were SFA, of which palmitic acid (C16:0) was present in the highest amounts. Another $33.0 \%$ of the total fatty acids were MUFA, with oleic acid (cis-C18:1n-9) as most abundant one. The percentage of PUFA was $11.4 \%$, consisting mostly of linoleic acid (C18:2n-6). In this study, pan-frying in margarine resulted in a significant increase in the total fatty acid content of cod and in a decrease in the total fatty acid content of salmon.

Cod is a lean fish species containing less than $1 \mathrm{~g}$ fat per $100 \mathrm{~g}$ fish. The most abundant fatty acids in the raw cod fillets in this study were palmitic acid (18.3\%), oleic acid (12.2\%), EPA (11.1\%) and DHA (38.6\%) (Table 1). Pan-frying of cod in margarine resulted in a large and significant increase in the total amount of fatty acids from $551 \mathrm{mg} / 100 \mathrm{~g}$ to $4149 \mathrm{mg} / 100 \mathrm{~g}$. Moreover, the increase was significant for all individual fatty acids, except for arachidonic acid (C20:4 $n-6$ ). Pan-frying in margarine also changed the fatty acid profile of cod. While the PUFA accounted for $56.0 \%$ of the total fatty acids in raw cod and the SFA for only $25.9 \%$, frying in margarine resulted in PUFA and SFA contents of $16.7 \%$ and $50.7 \%$, respectively. The $n-6 / n-3$ ratio altered from 0.10 before frying to 0.73 after pan-frying. In addition, whereas EPA and DHA accounted for $49.7 \%$ of the total fatty acids in the raw cod, they only counted for $9.8 \%$ after pan-frying.

Table 1

Contents of the main fatty acids (in $\mathrm{mg} / 100 \mathrm{~g}$ of product and in percentage) of unused margarine and of cod before and after pan-frying in margarine (means and SD) and the recoveries ${ }^{\mathrm{a}}(\%)$

\begin{tabular}{|c|c|c|c|c|c|c|c|}
\hline \multirow[t]{2}{*}{ Fatty acid } & \multicolumn{2}{|l|}{ Margarine $(n=2)$} & \multicolumn{5}{|l|}{$\operatorname{Cod}(n=4)$} \\
\hline & Unused (mg/100 g) & Unused (\%) & Raw $(\mathrm{mg} / 100 \mathrm{~g})$ & Pan-fried $(\mathrm{mg} / 100 \mathrm{~g})$ & Raw $(\%)$ & Pan-fried $(\%)$ & Recovery $^{\mathrm{a}}(\%)$ \\
\hline 12:0 & 11,094 (339) & 13.37 & n.d. & $489(93)^{* *}$ & 0.25 & 11.8 & $73.6(5.6)$ \\
\hline $14: 0$ & $5424(82)$ & 6.53 & $7(2)$ & $232(39)^{* *}$ & 1.25 & 5.60 & $71.9(3.6)$ \\
\hline $16: 0$ & $21,519(380)$ & 25.9 & $101(15)$ & $996(144)^{* * *}$ & 18.3 & 24.0 & $71.7(3.4)$ \\
\hline $18: 0$ & $6429(101)$ & 7.75 & $21(4)$ & $264(32)^{* * *}$ & 3.74 & 6.36 & $67.2(3.6)$ \\
\hline cis-18:1n-9 & $2564(707)$ & 30.89 & $67(18)$ & $1095(135)^{* * *}$ & 12.2 & 26.4 & $68.8(5.5)$ \\
\hline $18: 2 n-6$ & 7796 (129) & 9.39 & $9(3)$ & $314(38)^{* * *}$ & 1.65 & 7.57 & $62.4(7.5)$ \\
\hline $18: 3 n-3$ & $1476(9)$ & 1.78 & $4(2)$ & $61(6)^{* *}$ & 0.79 & 1.48 & $60.5(8.1)$ \\
\hline $20: 4 n-6$ & n.d. & - & $17(3)$ & $25(5)$ & 3.17 & 0.60 & $91.9(18.7)$ \\
\hline $20: 5 n-3$ & n.d. & - & $61(9)$ & $88(5)^{*}$ & 11.01 & 2.13 & $92.4(11.0)$ \\
\hline $22: 5 n-3$ & n.d. & - & n.d. & n.d. & - & - & - \\
\hline $22: 6 n-3$ & n.d. & - & $213(23)$ & $319(19)^{* *}$ & 38.6 & 7.70 & $102(3.5)$ \\
\hline$\sum \mathrm{SFA}^{\mathrm{b}}$ & $46,097(993)$ & 55.53 & 143 (29) & $2105(3278)^{* * *}$ & 25.9 & 50.7 & \\
\hline$\sum$ MUFA $^{\mathrm{c}}$ & $27,428(904)$ & 33.04 & $99(24)$ & $1227(153)^{* * *}$ & 18.0 & 29.6 & \\
\hline$\sum \mathrm{PUFA}^{\mathrm{d}}$ & 94,85 (439) & 11.43 & 309 (39) & $817(49)^{* * *}$ & $\begin{array}{l}10.0 \\
56.0\end{array}$ & $\begin{array}{l}29.0 \\
16.7\end{array}$ & \\
\hline$n-6 / n-3^{\mathrm{e}}$ & & & 0.10 & 0.73 & & & \\
\hline Total & 83,010 (2337) & 100.00 & $551(91)$ & $4149(525)^{* * *}$ & 100 & 100 & \\
\hline
\end{tabular}

n.d., not detected.

${ }^{\text {a }}$ Calculated as described in materials and methods.

b $\sum$ SFA also includes 8:0, 10:0, 15:0, 20:0, 22:0 and 24:0.

c $\sum$ MUFA also includes 14:1, 16:1, trans-18:1, cis-18:1n-11, 20:1, 22:1 and 24:1.

d $\sum$ PUFA also includes 18:3n-6, 18:4, 20:2 and 22:3.

e The $n-6 / n-3$ ratio is calculated taking into account C18:2n6, C18:3n6, C20:2n6, C20:4n6 and C18:3n3, C18:4n3, C20:3n3, C20:5n3, C22:5n3, C22:6n3.

${ }^{*} 0.01<P$ value $<0.05$.

${ }^{* *} 0.001<P$ value $\leqslant 0.01$.

${ }^{* * *} P$ value $\leqslant 0.001$. 
Table 2

Contents of the main fatty acids (in $\mathrm{mg} / 100 \mathrm{~g}$ of product and in percentage) of unused margarine and of salmon before and after pan-frying in margarine (means and SD) and the recoveries ${ }^{\mathrm{a}}(\%)$

\begin{tabular}{|c|c|c|c|c|c|c|c|}
\hline \multirow[t]{2}{*}{ Fatty acid } & \multicolumn{2}{|l|}{ Margarine $(n=2)$} & \multicolumn{5}{|l|}{ Salmon $(n=3)$} \\
\hline & Unused $(\mathrm{mg} / 100 \mathrm{~g})$ & Unused $(\%)$ & Raw (mg/100 g) & Pan-fried $(\mathrm{mg} / 100 \mathrm{~g})$ & Raw $(\%)$ & Pan-fried $(\%)$ & Recovery $^{\mathrm{a}}(\%)$ \\
\hline $12: 0$ & 11,094 (339) & 13.4 & $10(2)$ & $197(49)^{*}$ & 0.07 & 1.86 & $73.2(2.6)$ \\
\hline $14: 0$ & $5424(82)$ & 6.53 & $850(102)$ & $611(155)$ & 6.11 & 5.78 & $62.1(10.5)$ \\
\hline $16: 0$ & $21,519(380)$ & 25.9 & $1832(231)$ & $1572(264)$ & 13.2 & 14.9 & $66.5(8.8)$ \\
\hline $18: 0$ & $6429(101)$ & 7.75 & $350(61)$ & $344(44)$ & 2.51 & 3.26 & $67.3(8.7)$ \\
\hline cis-18:1n-9 & $25,642(707)$ & 30.9 & $2037(654)$ & $1692(364)$ & 14.6 & 16.0 & $65.6(11.6)$ \\
\hline $18: 2 n-6$ & 7796 (129) & 9.39 & $768(201)$ & $580(59)$ & 5.52 & 5.49 & $60.7(9.6)$ \\
\hline $18: 3 n-3$ & $1476(9)$ & 1.78 & $210(40)$ & $148(27)$ & 1.51 & 1.40 & $59.0(11.3)$ \\
\hline $20: 4 n-6$ & n.d. & - & $89(24)$ & $69(33)$ & 0.64 & 0.65 & $70.0(25.3)$ \\
\hline $20: 5 n-3$ & n.d. & - & $1122(218)$ & $746(230)$ & 8.07 & 7.06 & $61.3(15.0)$ \\
\hline $22: 5 n-3$ & n.d. & - & $60(10)$ & $40(15)$ & 0.43 & 0.38 & $61.8(23.2)$ \\
\hline $22: 6 n-3$ & n.d. & - & $1547(326)$ & $1156(170)$ & 11.1 & 10.9 & $69.0(17.3)$ \\
\hline$\sum \mathrm{SFA}^{\mathrm{b}}$ & 46,097 (993) & 55.53 & $3175(380)$ & $2871(466)$ & 22.82 & 27.15 & \\
\hline$\sum \mathrm{MUFA}^{\mathrm{c}}$ & $27,428(904)$ & 33.04 & $6603(1166)$ & $4750(983)$ & 47.46 & 44.93 & \\
\hline$\sum \mathrm{PUFA}^{\mathrm{d}}$ & 9485 (439) & 11.43 & $4135(742)$ & $2951(488)$ & 29.72 & 27.91 & \\
\hline$n-6 / n-3^{\mathrm{e}}$ & & & 0.30 & 0.32 & & & \\
\hline Total & $83,010(2337)$ & 100.00 & $13,914(2287)$ & $10,571(1721)$ & 100.00 & 100.00 & \\
\hline
\end{tabular}

n.d., not detected.

a Calculated as described in materials and methods.

b $\sum$ SFA also includes 8:0, 10:0, 15:0, 20:0, 22:0 and 24:0.

c $\sum$ MUFA also includes 14:1, 16:1, trans-18:1, cis-18:1n-11, 20:1, 22:1 and 24:1.

d $\sum$ PUFA also includes 18:3n-6, 18:4, 20:2 and 22:3.

e The $n-6 / n-3$ ratio is calculated taking into account $\mathrm{C} 18: 2 n 6, \mathrm{C} 18: 3 n 6, \mathrm{C} 20: 3 n 6, \mathrm{C} 20: 4 n 6$ and $\mathrm{C} 18: 3 n 3, \mathrm{C} 18: 4 n 3, \mathrm{C} 20: 3 n 3, \mathrm{C} 20: 5 n 3, \mathrm{C} 22: 5 n 3$, $\mathrm{C} 22: 6 n 3$.

* $0.01<P$ value $<0.05$

Salmon is a fatty fish with a fat content varying between 10 and $15 \%$. The most important fatty acids in the examined salmon fillets were palmitic acid (13.2\%), oleic acid (14.6\%), EPA (8.1\%) and DHA (11.1\%). Pan-frying of salmon fillets in margarine resulted in a decrease in the total fatty acid content from 13,914 to $10,571 \mathrm{mg} / 100 \mathrm{~g}$. This trend could be detected for all analysed fatty acids (but none were significant), except for lauric acid (C12:0), the amount of which increased significantly from 10 to $197 \mathrm{mg} / 100 \mathrm{~g}$ (Table 2). The content of EPA and DHA after pan-frying with margarine amounted only to, respectively $66.5 \%$ and $74.7 \%$ of the original content. After pan-frying, SFA accounted for $27.2 \%$ of the total fatty acids whereas this percentage was $22.8 \%$ before pan-frying. The changes were negligible for the percentage of PUFA. The $n-6 / n-3$ ratio altered from 0.30 before to 0.32 after pan-frying.

Table 3 shows the contents of SFA, MUFA and PUFA in the used margarine before and after pan-frying

Table 3

Contents of the fatty acid groups as percentage (means and SD) of margarine before and after pan-frying of cod and salmon

\begin{tabular}{llll}
\hline & $\begin{array}{l}\text { Unused } \\
\text { margarine } \\
(n=2)(\%)\end{array}$ & $\begin{array}{l}\text { Margarine } \\
\text { after pan-frying } \\
\text { cod }(n=3)(\%)\end{array}$ & $\begin{array}{l}\text { Margarine } \\
\text { after pan-frying } \\
\text { salmon }(n=3)(\%)\end{array}$ \\
\hline SFA $(\%)$ & $55.5 \pm 0.10$ & $57.7 \pm 3.00$ & $43.6 \pm 1.96$ \\
MUFA $(\%)$ & $33.0 \pm 0.30$ & $32.8 \pm 1.65$ & $39.8 \pm 2.04$ \\
PUFA $(\%)$ & $11.4 \pm 0.40$ & $9.46 \pm 1.42$ & $16.5 \pm 1.50$ \\
\hline
\end{tabular}

of the two fish species. In the case of cod fillets, the PUFA content decreased from $11.4 \%$ to $9.46 \%$ whereas it increased from $11.43 \%$ to $16.54 \%$ after pan-frying of salmon fillets. In the latter case, there were also notable decreases in the percentages of SFA and MUFA.

\subsection{Pan-frying in olive oil}

The fatty acid content of cod and salmon, before and after frying in olive oil, are shown in Tables 4 and 5. The olive oil used in this study was an unsaturated fat, with only $15.4 \%$ of the total fatty acid content consisting of SFA. The largest amount (76.1\%) consisted of MUFA, mostly represented by oleic acid. In olive oil, the percentage of PUFA was even smaller than in margarine: only $8.5 \%$ of the total fatty acid content was polyunsaturated. Pan- frying in olive oil resulted in an increase of the total fatty acid content in cod and in a decrease of the total fatty acid content in salmon.

When cod was pan-fried in olive oil, the total amount of fatty acids increased significantly from 559 to $2302 \mathrm{mg} / 100 \mathrm{~g}$ (Table 4). On an individual level, the increase was only significant for palmitic acid, oleic acid, linoleic acid, EPA and DHA. Pan-frying of cod fillets in olive oil resulted in decreases of the amounts of SFA and PUFA (from $23.9 \%$ to $18.6 \%$ and from $53.2 \%$ to $21.6 \%$, respectively) and in an increase of the amount of MUFA from $22.9 \%$ to $59.8 \%$. The $n-6 / n-3$ ratio altered from 0.10 before to 0.40 after pan-frying. 
Table 4

Contents of the main fatty acids (in $\mathrm{mg} / 100 \mathrm{~g}$ of product and in percentage) of unused olive oil and of cod before and after pan-frying in olive oil (means and SD) and recoveries ${ }^{\mathrm{a}}$

\begin{tabular}{|c|c|c|c|c|c|c|c|}
\hline \multirow[t]{2}{*}{ Fatty acid } & \multicolumn{2}{|l|}{ Olive oil $(n=2)$} & \multicolumn{5}{|l|}{$\operatorname{Cod}(n=3)$} \\
\hline & Unused $(\mathrm{mg} / 100 \mathrm{~g})$ & Unused $(\%)$ & $\operatorname{Raw}(\mathrm{mg} / 100 \mathrm{~g})$ & Pan fried $(\mathrm{mg} / 100 \mathrm{~g})$ & Raw $(\%)$ & Pan fried $(\%)$ & Recovery $^{\mathrm{a}}(\%)$ \\
\hline 12:0 & n.d. & - & n.d. & $3(1)$ & - & 0.12 & - \\
\hline 14:0 & n.d. & - & $5(1)$ & $11(4)$ & 0.94 & 0.46 & - \\
\hline $16: 0$ & $11,527(143)$ & 11.6 & $101(13)$ & $327(38)^{* *}$ & 18.1 & 14.2 & $59.0(3.8)$ \\
\hline $18: 0$ & $3100(24)$ & 3.11 & $20(3)$ & $73(13)$ & 3.60 & 3.16 & $53.8(2.7)$ \\
\hline cis-18:1n-9 & 71,153 (1317) & 71.5 & $103(68)$ & $1276(265)^{*}$ & 18.4 & 55.4 & $49.3(5.2)$ \\
\hline $18: 2 n-6$ & 7286 & 7.32 & $11(6)$ & $121(19)^{*}$ & 2.05 & 5.25 & $41.9(6.2)$ \\
\hline $18: 3 n-3$ & $631(60)$ & 0.63 & $3(1)$ & $15(1)$ & 0.58 & 0.63 & $44.2(7.9)$ \\
\hline $20: 4 n-6$ & n.d. & - & $15(2)$ & $20(2)$ & 2.69 & 0.87 & $94.5(19.1)$ \\
\hline $20: 5 n-3$ & n.d. & - & $55(4)$ & $74(2)^{*}$ & 9.90 & 3.22 & $75.3(3.0)$ \\
\hline $22: 5 n-3$ & n.d. & - & n.d. & n.d. & - & - & - \\
\hline $22: 6 n-3$ & n.d. & - & $209(6)$ & $262(28)^{*}$ & 37.5 & 11.4 & $79.9(5.1)$ \\
\hline$\sum \mathrm{SFA}^{\mathrm{b}}$ & $15,324(323)$ & 15.4 & $133(16)$ & $428(55)^{*}$ & 23.9 & 18.6 & \\
\hline$\sum$ MUFA $^{\mathrm{c}}$ & $75,742(2339)$ & 76.10 & $128(71)$ & $1376(267)^{*}$ & 22.9 & 59.8 & \\
\hline$\sum$ PUFA $^{\mathrm{d}}$ & $8468(447)$ & 8.51 & $297(11)$ & $497(29)^{*}$ & 53.2 & 21.6 & \\
\hline$n-6 / n-3^{\mathrm{e}}$ & & & 0.10 & 0.40 & & & \\
\hline Total & $99,533(3108)$ & 100.00 & $558(97)$ & $2302(323)^{* *}$ & 100 & 100 & \\
\hline
\end{tabular}

n.d., not detected.

${ }^{a}$ Calculated as described in materials and methods.

b $\sum$ SFA also includes 8:0, 10:0, 15:0, 20:0, 22:0 and 24:0.

c $\sum$ MUFA also includes 14:1, 16:1, trans-18:1, cis-18:1n - 11, 20:1, 22:1 and 24:1.

d $\sum$ PUFA also includes 18:3n-6,18:4, 20:2 and 22:3.

e The $n-6 / n-3$ ratio is calculated taking into account C18:2n6, C18:3n6, C20:3n6, C20:4n6 and C18:3n3, C18:4n3, C20:3n3, C20:5n3, C22:5n3, C22:6n3.

${ }^{*} 0.01<P$ value $<0.05$.

** $0.001<P$ value $\leqslant 0.01$.

Table 5

Contents of the main fatty acids (in $\mathrm{mg} / 100 \mathrm{~g}$ of product and in percentage) of unused olive oil and of salmon before and after pan frying in olive oil (means and SD) and recoveries ${ }^{\mathrm{a}}$

\begin{tabular}{|c|c|c|c|c|c|c|c|}
\hline \multirow[t]{2}{*}{ Fatty acid } & \multicolumn{2}{|l|}{ Olive oil $(n=2)$} & \multicolumn{5}{|l|}{ Salmon $(n=3)$} \\
\hline & Unused (mg/100 g) & Unused (\%) & Raw (mg/100 g) & Pan fried $(\mathrm{mg} / 100 \mathrm{~g})$ & Raw $(\%)$ & Pan fried $(\%)$ & Recovery $^{1}(\%)$ \\
\hline 12:0 & n.d. & - & $11(3)$ & n.d. & 0.07 & - & - \\
\hline 14:0 & n.d. & - & 937 (187) & $683(196)^{*}$ & 6.10 & 5.28 & $74.1(9.2)$ \\
\hline 16:0 & $11,527(143)$ & 11.6 & $1788(314)$ & 1605 (349) & 11.7 & 12.4 & $85.5(9.1)$ \\
\hline 18:0 & $3100(24)$ & 3.11 & $315(55)$ & $297(51)$ & 2.05 & 2.29 & $84.9(8.1)$ \\
\hline cis-18:1n-9 & 71153 (1317) & 71.5 & $2411(247)$ & $2605(267)$ & 15.7 & 20.1 & $82.8(10.4)$ \\
\hline $18: 2 n-6$ & $7286(36)$ & 7.32 & $812(118)$ & $635(67)$ & 5.29 & 4.90 & $74.4(12.0)$ \\
\hline $18: 3 n-3$ & $631(60)$ & 0.63 & $224(35)$ & $159(13)$ & 1.46 & 1.23 & $71.8(13.8)$ \\
\hline $20: 4 n-6$ & n.d. & - & $60(8)$ & $51(7)$ & 0.39 & 0.39 & $85.5(6.9)$ \\
\hline $20: 5 n-3$ & n.d. & - & $1035(195)$ & $793(247)$ & 6.74 & 6.13 & $74.0(12.8)$ \\
\hline $22: 5 n-3$ & n.d. & - & $59(10)$ & $41(12)^{*}$ & 0.38 & 0.32 & $70.9(10.2)$ \\
\hline $22: 6 n-3$ & n.d. & - & $1329(206)$ & $1175(242)$ & 8.65 & 9.08 & $87.0(14.0)$ \\
\hline$\sum \mathrm{SFA}^{\mathrm{b}}$ & $15,324(323)$ & 15.4 & $3211(580)$ & $2730(604)$ & 20.9 & 21.1 & \\
\hline$\sum$ MUFA $^{\mathrm{c}}$ & $75,742(2339)$ & 76.10 & 8273 (1243) & $7117(1526)$ & 53.9 & 55.0 & \\
\hline$\sum$ PUFA $^{\mathrm{d}}$ & $8468(447)$ & 8.51 & $3868(571)$ & $3100(638)$ & 25.20 & 24.0 & \\
\hline$n-6 / n-3^{\mathrm{e}}$ & & & 0.34 & 0.32 & & & \\
\hline Total & $99,533(3108)$ & 100 & 15,353 (2394) & 12,947 (2759) & 100 & 100 & \\
\hline
\end{tabular}

n.d., not detected.

a Calculated as described in materials and methods.

b $\sum$ SFA also includes 8:0, 10:0, 15:0, 20:0, 22:0 and 24:0.

c $\sum$ MUFA also includes 14:1, 16:1, trans-18:1, cis-18:1n - 11, 20:1, 22:1 and 24:1.

d $\sum$ PUFA also includes 18:3n-6, 18:4, 20:2 and 22:3.

e The $n-6 / n-3$ ratio is calculated taking into account $\mathrm{C} 18: 2 n 6, \mathrm{C} 18: 3 n 6, \mathrm{C} 20: 3 n 6, \mathrm{C} 20: 4 n 6$ and $\mathrm{C} 18: 3 n 3, \mathrm{C} 18: 4 n 3, \mathrm{C} 20: 3 n 3, \mathrm{C} 20: 5 n 3, \mathrm{C} 22: 5 n 3$, C22:6n3.

${ }^{*} 0.01<P$ value $<0.05$ 
Table 6

Contents of the fatty acid groups in percentage (means and SD) of olive oil before and after pan-frying of cod and salmon

\begin{tabular}{llll}
\hline & $\begin{array}{l}\text { Unused } \\
\text { olive oil } \\
(n=2)(\%)\end{array}$ & $\begin{array}{l}\text { Olive oil after } \\
\text { pan-frying cod } \\
(n=3)(\%)\end{array}$ & $\begin{array}{l}\text { Olive oil after } \\
\text { pan-frying salmon } \\
(n=3)(\%)\end{array}$ \\
\hline SFA $(\%)$ & $15.4 \pm 0.28$ & $18.4 \pm 1.72$ & $17.8 \pm 0.49$ \\
MUFA $(\%)$ & $76.1 \pm 0.73$ & $75.1 \pm 1.57$ & $70.0 \pm 1.01$ \\
PUFA (\%) & $8.51 \pm 0.45$ & $6.49 \pm 0.25$ & $12.2 \pm 0.56$ \\
\hline
\end{tabular}

Pan-frying of salmon fillets in olive oil caused a decrease of the total fatty acid content from 15,353 to $12,947 \mathrm{mg} / 100 \mathrm{~g}$, which was not significant according to the $T$-test (Table 5). On an individual level, a decrease took place in almost all fatty acids, but was only significant for myristic acid (C14:0) and docosapentaenoic acid $(\mathrm{C} 22: 5 n-3)$. The only exception was the insignificant increase in oleic acid, which was the most abundant fatty acid in the used culinary fat. Pan-frying in olive oil did not affect the fatty acid profile in a significant way. The $n-6 / n-3$ ratio altered from 0.34 before to 0.32 after pan-frying.

Table 6 shows the contents of SFA, MUFA and PUFA in the used olive oil, before and after pan-frying of the two fish species. In the case of cod fillets, the PUFA content decreased from $8.51 \%$ to $6.49 \%$ whereas it increased from $8.51 \%$ to $12.2 \%$ after pan-frying of salmon fillets. Over the whole study, the mean recoveries varied between $41.9 \%$ and $102 \%$ for the cod samples and between $59.0 \%$ and $87.0 \%$ for the salmon samples (Table 1, 2, 4 and 5).

\section{Discussion}

Pan-frying in margarine, as well as in olive oil, significantly increased the total fatty acid content in the case of cod fillets and resulted in a decreasing trend in the case of salmon fillets. Consequently, this study showed that the uptake of fatty acids from the culinary fat into the fried samples was inversely correlated with the total fatty acid content of the fish. Using margarine increased the percentage of SFA in both species, whereas, using olive oil increased the percentage of MUFA. Hence, control over the fatty acid composition of the consumed fried fish can be achieved to some extent by the selection of the culinary fat. Moreover, the results show that it is important to take into account the effect of processing when estimating fatty acid intake.

From a methodological point of view, three remarks have to be made before discussing the results. First, when comparing the results for the lean fish and the fatty fish samples, the difference in thickness of the samples may have had an influence (respectively, 2.0 and $2.5 \mathrm{~cm}$ for the cod and salmon samples). Secondly, the absolute numerical values of the fatty acid contents have to be interpreted carefully, taking into consideration that the fatty acid content and composition of fish samples is variable and influenced by size, age and season. This variation was partially reduced by using frozen fish fillets which are made of mixed muscle meat of different individual fishes of the same species. On the other hand, Cantwell (2000) reported that margarine manufacturers may change their fat ingredients used for reasons of cost, which changes the fatty acid composition of their products from season-to-season. Thirdly, there is no standard rule about the number of samples that must be prepared and analysed in this kind of investigation, nor about the final core temperature that must be reached.

Possible mechanisms for the changes happened occurring the culinary process are absorption of culinary fat in the fish, moisture loss of the food, leaching of fatsoluble molecules out of the food and oxidation reactions with free radicals generated in the hot culinary fat (Little, Armstrong, \& Bergan, 2000). The two first mechanisms result in an increase in the amount of fatty acids, the other ones in a decrease. In the case of oxidation, it is important to note that different fatty acids respond in different ways to a heat treatment. Saturated fatty acids are fairly stable to heat in the range of temperatures commonly encountered during cooking. However, above $150{ }^{\circ} \mathrm{C}$, and when oxygen is present, a variety of oxidation products can be detected. It must be noted that although the final internal temperature of the samples does not exceed $65^{\circ} \mathrm{C}$, much higher temperatures are reached in the cooking oil and at the surface of the samples, since the surface temperature of the heating unit was $234^{\circ} \mathrm{C}$ for the cod samples and $190{ }^{\circ} \mathrm{C}$ for the salmon samples. Unsaturated fatty acids are far more heat-labile, with instability increasing with the degree of unsaturation. In combination with oxygen, PUFA degradation occurs more readily and PUFA undergo pronounced oxidative effects (Little et al., 2000). On the other hand, highly unsaturated biological tissues usually also contain a high level of the natural antioxidant vitamin E (Little et al., 2000): cod and salmon contain 0.4 and $1.9 \mathrm{mg}$ vitamin $\mathrm{E}$ per $100 \mathrm{~g}$, respectively (Beemster et al., 2001).

Concerning the changes in the total amount of fatty acids before and after pan-frying, two important remarks can be made. First, pan-frying of cod fillets resulted in an increased fatty acid content for both culinary fats, whereas, in the salmon fillets, the opposite trend was seen. Secondly, for both fish species, these alterations were larger when using margarine then when using olive oil. Varela (1988) indicated that olive oil forms a crust that protects the food against absorption of oils, whereas other fats do not form such a definite crust. During frying, this crust may hinder fat uptake in cod fillets, on the one hand, and fat loss in salmon fillets on the other hand. 
The analyses done in this study on the raw samples showed that the contributions of EPA and DHA to the total fatty acid content in salmon were lower than in cod. However, in view of the much higher fat content of salmon, it is clear that salmon is a far more important food source of these health-beneficial fatty acids: $274 \mathrm{mg} / 100 \mathrm{~g}$ EPA and DHA in raw cod fillets versus $2,669 \mathrm{mg} / 100 \mathrm{~g}$ in raw salmon fillets. Therefore, cod does not represent an important food source of these health beneficial fatty acids, even though the fat of raw cod is rich in $n-3$ PUFA. The EPA and DHA content of the analyzed raw cod is comparable to what was found by Candela et al. (1997), i.e. $250 \mathrm{mg} / 100 \mathrm{~g}$ of EPA and DHA in raw cod. However, they only found a content of $1527 \mathrm{mg} / 100 \mathrm{~g}$ of EPA and DHA in raw salmon (Candela et al., 1997). This discrepancy must be explained by seasonal difference and/or size and age of the fish.

The results showed that the pan-frying of cod fillets in margarine and olive oil resulted in a significant increase in the total amount of fatty acids. The increase in the absolute amount of EPA and DHA in cod, when using margarine, can only be explained by moisture loss during frying, because the margarine used does not contain those fatty acids. Furthermore, the fatty acid profile of cod altered in such a way that it more closely resembled the profile of the used margarine, which confirms that absorption of culinary fat is an important explanation for the increase in fatty acid content. Comparing the changes in MUFA contents of cod and salmon when using margarine confirms this statement. The percentage of MUFA in raw cod fillets (18.4\%), which was lower than that of the margarine $(33.0 \%)$, increased during frying $(29.6 \%)$. On the other hand, the percentage of MUFA in raw salmon fillets $(47.5 \%)$, which was higher than that of the margarine, decreased during frying $(44.9 \%)$. Using olive oil involves an exchange of fatty acids between the fat in the cod and the culinary fat used, which caused significant changes in the fatty acid composition, resulting in a decrease in the percentage of SFA and PUFA and in an increase in the percentage of MUFA. The increase in the absolute amounts of SFA and PUFA (in $\mathrm{mg} / 100 \mathrm{~g}$ ) must be explained by moisture loss during pan-frying. Also here, the pattern of fatty acids in cod changed in the direction of the fatty acid profile of the used culinary fat. The increase in the absolute amount of other fatty acids, can on the one hand, be explained by losses of water, but on the other hand, was the result of absorption of the fatty acids from the culinary fat used for frying. When using margarine as well as olive oil, it is possible that some fat migration out of the cod fillet took place, but it is clear that fatty acid absorption was more dominant. Moreover, a test of pan-frying of cod fillets without any culinary fat made it clear that fat loss from cod was minimal. Our findings are comparable to results of studies on the effect of deep fat frying on lean fish (Agren \& Hanninen, 1993; Candela et al., 1997; Gall et al., 1983; Little et al., 2000; Mai et al., 1978). Each study showed an increase in the total amount of fat during frying, to result in a fatty acid profile that became similar to that of the used cooking fat. Candela et al. (1997) concluded that the contribution of EPA and DHA to the total amount of fat of cod decreased strongly after deep fat-frying in sunflower oil.

Pan-frying of salmon fillets resulted in a decrease of the total fatty acid content, which was not significant according to the $T$-test. The decrease was smaller when using olive oil. The losses can be explained by migration of fat out of the fillets during frying. For the unsaturated fatty acids, oxidation reactions can be a supplemental cause of degradation. A test of pan-frying salmon without any culinary fat made it clear that salmon loses fat during pan-frying. The most important fatty acids found in the lost fat are those that are most abundant in salmon. In addition, the increase in the absolute amount of PUFA in the used culinary fat after pan-frying of salmon confirms the migration of fatty acids from the salmon. However, the increase of lauric acid (C12:0) after using margarine as culinary fat, shows that there must also be absorption of fatty acids from the culinary fat to the fillets. The decreases in the different fatty acids, after using olive oil, resulted in a contribution of MUFA to the total fatty acid content. Not surprisingly, MUFA forms the largest fraction of the used olive oil, which shows that there must be interaction between the salmon fillets and the culinary fat. Also Al Saghir et al. (2004) found that the exchange between salmon and olive oil is marginal and mostly detectable as a slight modification in the fatty acid profile. On the other hand, Candela et al. (1998) reported that deep fat-frying of salmon did not significantly affect the fat content, as also did Mai et al. (1978) for other species of fatty fish. Sanchez-Muniz et al. (1992) found equal results for sardines after deep frying with different culinary fats (olive oil, sunflower oil and lard).

From a public health point of view, it is important to mention that the $n-6 / n-3$ ratio in the cod fillets altered from 0.10 before to 0.74 after pan-frying when using margarine. A less pronounced change (from 0.10 to 0.40 ) was found when using olive oil. This ratio increase is an undesired effect since it affects the benefits related to the intake of EPA and DHA. Consequently, using olive oil for the pan-frying of cod seems preferable to using margarine. Despite the important changes in $n-6 / n-3$ ratio during the pan-frying of cod fillets, the $n-6 / n-3$ ratio alterations found in salmon fillets were negligible (from 0.30 to 0.32 and from 0.34 to 0.32 when using, respectively, margarine and olive oil).

The results show that the pan-frying process also altered the content and composition of the residues of the culinary fat. A possible explanation for the decrease 
in the percentage of PUFA in the culinary fat, after frying of cod, is oxidation of PUFA, in view of the high temperature of the cooking surface in combination with the presence of oxygen. On the other hand, the panfrying of salmon resulted in an increase in the percentage of PUFA in the used culinary fat. Probably, this is due to fat migration from the salmon fillets, that overcompensated for the decrease caused by oxidation.

Recoveries below $100 \%$ must be mainly explained by fat losses. Fat losses are caused by sparkling out of the pan, as well as by incomplete recovery of the fat residue in the pan after the frying process. Moreover, high recoveries are difficult to achieve when performing analyses on samples with relatively low concentrations of fat. The rather low recoveries illustrate the difficulties related to this kind of experiment.

\section{Conclusions}

The effect of the pan-frying of fish fillets depends on the total fatty acid content of the fish and on the fatty acid profile of the culinary fat used. In lean fish, a significant increase in the amount of fatty acids was detected, leading to a fatty acid profile similar to the profile of the culinary fat used. In fatty fish, there was a trend for a decrease in the total fatty acid content. The alterations of the fatty acid profile of the fatty fish also changed the fatty acid profile in the direction of that of the culinary fat. Control over the fatty acid content and composition of the consumed food can therefore be influenced by the selected culinary fat. The study clearly showed that an intake assessment of fatty acids on the basis of raw food products may differ significantly from an assessment based on the fatty acid content of prepared food products. Since the health properties of fatty acids depend largely on their structure, the possible changes in fatty acid content during processing of food items have to be taken into account.

\section{Acknowledgements}

The authors gratefully acknowledge financial support from the Belgian Science Policy through the SPSD II project $\mathrm{CP} / 02 / 56$ and the Institute for the Promotion of Innovation through Science and Technology in Flanders (IWT-Vlaanderen).

\section{References}

Agren, J. J., \& Hanninen, O. (1993). Effects of cooking on the fattyacids of 3 fresh-water fish species. Food Chemistry, 46(4), 377-382.

Al Saghir, S., Thurner, K., Wagner, K. H., Frisch, G., Luf, W., Razzazi-Fazeli, E., et al. (2004). Effects of different cooking procedures on lipid quality and cholesterol oxidation of farmed salmon fish (Salmo salar). Journal of Agricultural and Food Chemistry, 52(16), 5290-5296.

Aro, T., Tahvonene, R., Mattila, T., Nurmi, J., Sivonen, T., \& Kallio, H. (2000). Effects of season and processing on oil content and fatty acids of Baltic herring (Clupea harengus membras). Journal of Agricultural and Food Chemistry, 48, 6085-6093.

Bandarra, N. M., Batista, I., Nunes, M. L., Empis, J. M., \& Christie, W. W. (1997). Seasonal changes in lipid composition of sardine (Sardina pilchardus). Journal of Food Science, 62(1), $40-42$.

Beemster, C. J. M., van der Heijden, L. J. M., Hulshof, K. F. A. M., Langius, J. A. E., van Oosten, H. M., Pruissen-Boskaljon, J. C., et al. (2001). Nevo-tabel. Nederlands voedingsstoffenbestand. Den Haag: Nederlands Voedingscentrum.

Candela, M., Astiasaran, I., \& Bello, J. (1997). Effects of frying and warmholding on fatty acids and cholesterol of sole (Solea solea), codfish (Gadus morhua) and hake (Merluccius merluccius). Food Chemistry, 58(3), 227-231.

Candela, M., Astiasaran, I., \& Bello, J. (1998). Deep-fat frying modifies high-fat fish lipid fraction. Journal of Agricultural and Food Chemistry, 46(7), 2793-2796.

Cantwell, M. M. (2000). Assessment of individual fatty acid intake. Proceedings of the Nutrition Society, 59(2), 187-191.

Cunnane, S. C., \& Griffin, B. A. (2002). Nutrition and metabolism of lipids. In M. J. Gibney, H. H. Vorster, \& F. J. Kok (Eds.), Introduction to human nutrition (pp. 81-115). Oxford: Blackwell Science, Ltd..

Din, J. N., Newby, D. E., \& Flapan, A. D. (2004). Science, medicine, and the future - Omega 3 fatty acids and cardiovascular disease fishing for a natural treatment. British Medical Journal, 328(7430), $30-35$.

Folch, J., Lee, M., \& Sloane-Stanley, G. H. (1957). A simple method for the isolation and purification of total lipids from animal tissues. Journal of Biological Chemistry, 226, 497-509.

Gall, K. L., Otwell, W. S., Koburger, J. A., \& Appledorf, H. (1983). Effects of 4 cooking methods on the proximate, mineral and fattyacid composition of fish fillets. Journal of Food Science, 48(4), 1068-1074.

Hamre, K., Lie, O., \& Sandnes, K. (2003). Seasonal development of nutrient composition, lipid oxidation and colour of fillets from Norwegian spring-spawning herring (Clupea harengus L.). Food Chemistry, 82(3), 441-446.

Hoge, Gezondheidsraad (2004). Recommandations et allegations concernant les acides gras omega-3. Brussels: Hoge Gezondheidsraad.

Kris-Etherton, P. M., Harris, W. S., \& Appel, L. J. (2003). Omega-3 fatty acids and cardiovascular disease - new recommendations from the American Heart Association. Arteriosclerosis Thrombosis and Vascular Biology, 23(2), 151-152.

Little, S. O., Armstrong, S. G., Bergan, \& J. G. (2000). Factors affecting stability and nutritive value of fatty acids: Culinary practices (Vol. 2, pp. 427-437).

Mai, J., Shimp, J., Weihrauch, J., \& Kinsella, J. E. (1978). Lipids of fish fillets - changes following cooking by different methods. Journal of Food Science, 43(6), 1669-1674.

Mustafa, F. A., \& Medeiros, D. M. (1985). Proximate composition, mineral-content, and fatty-acids of catfish (Ictalurus-punctatus, rafinesque) for different seasons and cooking methods. Journal of Food Science, 50(3), 585-588.

Nettleton, J. A., \& Exler, J. (1992). Nutrients in wild and farmed fish and shellfish. Journal of Food Science, 57(2), 257-260.

Olsson, G. B., Olsen, R. L., Carlehog, M., \& Ofstad, R. (2003). Seasonal variations in chemical and sensory characteristics of farmed and wild Atlantic halibut (Hippoglossus hippoglossus). Aquaculture, 217(1-4), 191-205.

Raes, K., De Smet, S., \& Demeyer, D. (2001). Effect of doublemuscling in Belgian Blue young bulls on the intramuscular 
fatty acid composition with emphasis on conjugated linoleic acid and polyunsaturated fatty acids. Animal Science, 73, 253-260.

Sanchez-Muniz, F. J., Viejo, J. M., \& Medina, R. (1992). Deep-frying of sardines in different culinary fats. Changes in the fatty acid composition of sardines and frying fats. Journal of Agriculture and Food Chemistry, 40, 2252-2256.

Varela, G. (1988). Current facts about the frying of food. In G. Varela, A. E. Bender, \& I. D. Morton (Eds.), Frying of food. Principles, changes, new approaches. Chichester: Ellis Horwood. 